to make them all the same length. This tends to mask inequalities in rates of substitution along the different branches. More subtly, to keep all the horizontal branches parallel, it is necessary to introduce vertical lines of various lengths. These lines, which correspond to no feature of the data, impart an artificial air of organization to the tree - the bushier the main branches of the tree,

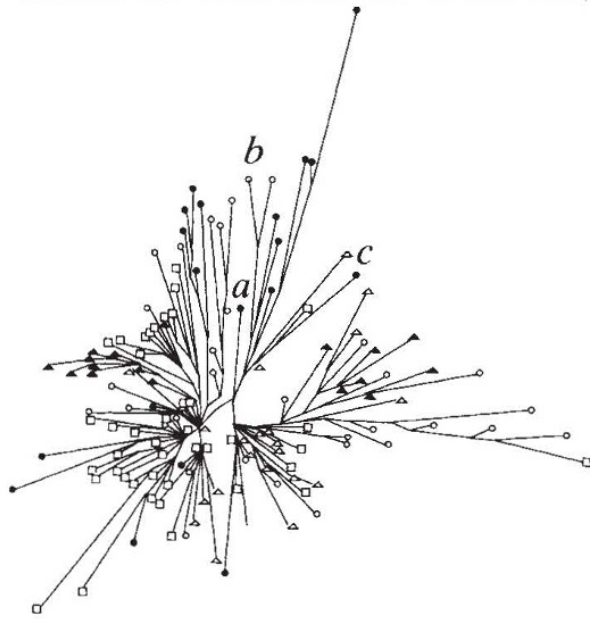

Starburst plot of the data of Cann et al. ${ }^{1}$. a, Position of the lone African bushman in the sample; $b$, the anomalous Asian members of the 'African' branch; $c$, position of an Australian aboriginal near the same branch. Note another aboriginal at the base of the branch. Black circles, African ancestry; open squares, European; open triangles, Australian Aborigine; closed triangles, New Guinea; open circles, Asian.

the longer the vertical lines must be to separate them.

The effect of these distortions can be removed by redrawing the original data of Cann et al. so as to preserve the varying lengths of the branches and to avoid introducing any arbitrary separations between them (see figure). The result is an unrooted tree like a starburst, with the viewer looking back in time, and with the origin of the tree somewhere in the middle of the starburst. The tree shown is one of the many trees that are shorter than the original one, trees that can easily be generated by PAUP', and the 'African' branch is near 12 o'clock. In this typical tree, the branch includes Asians, with one European and two Aborigines very close to it. When the data are looked at in this way, the impossibility of positioning the tree's origin with any certainty can easily be understood.

The starburst plot emphasizes the remarkable overdispersal of the data, with very unequal branch lengths and members of most groups scattered from the centre of the starburst to its periphery. These data are not alone in showing this overdispersed character, which has bedeviled the construction of phylogenetic trees from the beginning ${ }^{9}$. The impor- tant question now becomes whether it is possible, by some combination of population subdivision, migration and fluctuating population sizes, to generate such a tree assuming a constant rate of neutral mutations, or whether it is necessary to postulate fluctuating mutation rates and/or selective pressures in the various branches.

CHRISTOPHER WILLS

Department of Biology 0116 ,

University of California, San Diego,

La Jolla, California 92093, USA

1. Cann, R. L., Stoneking. M. \& Wilson, A. C. Nature 325 31-36 (1987)

. Vigilant, L., Stoneking. M., Harpending, H., Hawkes, K. \& Wilson, A. C. Science 253. 1503-1507 (1991)

3. Templeton, A. R. Science 255, 737 (1992)

4. Hedges, S. B. Kumar, S. Tamura, K. \& Stoneking, M Science 255. 737-739 (1992).

5. Maddison, D R. Syst. Zool. 40, 355-363 (1991)

6. Gee, H. Nature 355. 583 (1992)

. Wills, C. in Biocomputing: Genome Sequence Analysis (ed. Smith, D. W (Academic in the press).

8. Swofford D L PAUP 30 User's Manual (Draft 2/9/91) (lllinois Natural History Suney Champaign 1991).

Felsenstein, J. A. Rev. Genet. 22, 521-565 (1988).

\section{Toroidal bubbles}

SIR - The discussion about toroidal air bubbles by Daedalus ${ }^{1}$ and Spisak $^{2}$ prompts me to mention our exhibit called "Friendship Acrobatic Troupe" by artist-in-residence Carl Cheng, in which a series of toroidal bubbles are formed in a 4-foot-deep transparent water tank through the actuation of a valved air jet. These toroidal bubbles float to the surface in an almost perfect ring. Smaller, detached bubbles clearly show the rota-

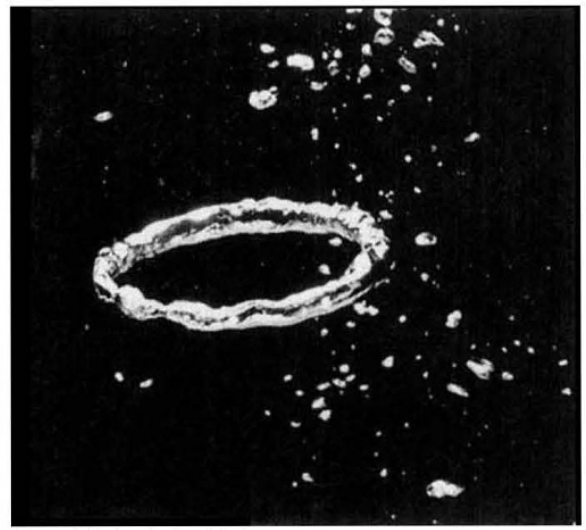

Toroidal air bubble.

tional flow of the liquid around the outside of the air ring. The toroidal rings are remarkably stable as they ascend up the tank (see figure). The bubbles are particularly beautiful because of the silver reflection produced by the light, which is incident directly from above and reflects due to total internal reflection.

\section{Exploratorium,}

ROBERT J. SEMPER

\section{Lyon St, San Francisco.} California 94123, USA

1. Jones, D. Nature 343, 122 (1990). 2. Spisak, W. Nature 349, 23 (1991).

\section{Alzheimer's a correction}

SIR - Lucotte and colleagues reported in Scientific Correspondence ${ }^{1}$ the occurrence of a mutation (valine for isoleucine) in the $\beta$-amyloid precursor protein (APP) in a family in which both dementia and congophilic angiopathy occurs. G. A. and A. D. were responsible for the clinical assessment, DNA collection and neuropathological assessment of individuals from this family.

We have now carried out a further analysis of the APP gene. We used a $B c l$ I digest of the amplified product of exon 17 as a method for screening for the mutation ${ }^{2}$. Despite the fact that we could detect the mutation in positive controls, $B c l$ I failed to digest any samples from this family. Therefore, we sequenced exons 16 and 17 of the amplified product, which revealed these exons to be of normal sequence in this family. Thus we regard the report by Lucotte and colleagues of the mutation in this family to be unreliable.

The valine to isoleucine mutation in exon 17 of the APP gene has been reported in six other families with Alzheimer's disease ${ }^{2-4}$; in these families its presence has been confirmed by direct sequencing. Further, two other mutations in the same amino acid have been reported ${ }^{5,6}$. Thus, we are confident that mutations to this amino acid can cause Alzheimer's disease. We recommend that the occurrence of all mutations should be confirmed by direct sequencing.

The range of the phenotype of the mutation in exon 17 remains to be precisely delineated. Clearly, however, the age of onset of the disease is a variable feature (about 48 to about 60 years) as is the occurrence of Lewy bodies ${ }^{2}$. So far, no patients in which this mutation has been confirmed have more than modest congophilic angiopathy.

FIONA CRAWFORD
MARIE-Christine CHARTIER-HARLIN
MIKE MULLAN
JOHN HARDY

Alzheimer's Disease Research Group, St Mary's Hospital Medical School. London W2 1PG, UK

ANDRÉ DELACOURTE GENEVIEVE ARNOTT

\section{U156 INSERM.}

Place de Verdun,

59045 Lille,

France

1. Lucotte, G., Berriche, S. \& David, F. Nature 351, 530 (1991).

2. Hardy, J. et al. Lancet 337, 1342-1343 (1991)

Goate, A. et al. Nature 349, 704-706 (1991)

Naruse, S. et al. Lancet 337, 978-979 (1991)

Murrell, J., Farlow, M., Ghetti, B. \& Benson, M. Science 254. 7 (1991)

Chartier-Harlin. M. C. et al. Nature 353, 844-846 (1991).

NATURE $\cdot$ VOL $356 \cdot 2$ APRIL 1992 